\title{
Fuel Oil Production from Two-Stage Pyrolysis-Catalytic Reforming of Brominated High Impact Polystyrene Using Zeolite and Iron Oxide Loaded Zeolite Catalysts
}

\author{
Hu Wu, Yafei Shen, Dachao Ma, Qi An, Noboru Harada, Kunio Yoshikawa \\ Department of Environmental Science and Technology, Tokyo Institute of Technology, Yokohama, Japan \\ Email: wuhu2010wuhu@gmail.com
}

Received 16 December 2014; accepted 26 March 2015; published 7 April 2015

Copyright (C) 2015 by authors and Scientific Research Publishing Inc.

This work is licensed under the Creative Commons Attribution International License (CC BY).

http://creativecommons.org/licenses/by/4.0/

(c) (i) Open Access

\section{Abstract}

The experiments of two-stage pyrolysis and catalytic reforming of high impact polystyrene (HIPS) containing brominated flame retardants and antimony trioxide $\left(\mathrm{Sb}_{2} \mathrm{O}_{3}\right)$ were conducted in the presence of four zeolite catalysts in order to remove the bromine content from the derived oil products. The four catalysts used were natural zeolite (NZ), iron oxide loaded natural zeolite (Fe-NZ), HY zeolite (YZ) and iron oxide loaded HY zeolite (Fe-NZ). The effect of catalyst types on the product yield, the gas and oil product composition and the debromination efficiency of the oil products was evaluated in details. The results showed that the loading of iron oxides reduced the pore size and surface areas of natural zeolite and HY zeolite. Regardless of the presence of catalysts, the single-ring aromatic compounds were the main components of the oil products, such as ethylbenzene, toluene, styrene and cumene. Meanwhile, when YZ and Fe-YZ were used, the tworing and multi-ring aromatic compounds in the oils, as well as the yield of gas products, significantly increased at the expense of valuable single-ring aromatic compounds. Furthermore, in terms of the debromination performance of the oil products, Fe-NZ and Fe-YZ were better than NZ and $\mathrm{YZ}$, duo to the loading of iron oxide, which could react with derived $\mathrm{HBr}$ and then remove more bromine from the oil products.

\section{Keywords}

Frame Retarded HIPS, Pyrolysis, Catalytic Reforming, Debromination, Zeolites

\section{Introduction}

As the development of technology and economy, the consumption and replacement of electronic and electrical

How to cite this paper: Wu, H., Shen, Y.F., Ma, D.C., An, Q., Harada, N. and Yoshikawa, K. (2015) Fuel Oil Production from Two-Stage Pyrolysis-Catalytic Reforming of Brominated High Impact Polystyrene Using Zeolite and Iron Oxide Loaded Zeolite Catalysts. Open Journal of Ecology, 5, 136-146. http://dx.doi.org/10.4236/oje.2015.54012 
equipment are increasing by an alarming rate. Thus, large quantities of waste electrical and electronic equipment (WEEE) are produced and have become a major stream of solid wastes in the nations worldwide [1]-[3]. However, the disposal of WEEE becomes a global problem because of its complicated composition. In terms of the plastic content of WEEE, there are 15 different types of engineering plastics used in WEEE, such as high impact polystyrene (HIPS), acrylonitrile-butadiene-styrene (ABS), polyamide (PA) and polycarbonate (PC) [2]. Among them, high-impact polystyrene (HIPS) is widely used for electrical and electronic equipment and building materials. HIPS is a composite material consisting of a PS phase and a dispersed polybutadiene (PB) rubber phase. In order to reduce the flammability of HIPS plastics, polybrominated compounds and antimony trioxide $\left(\mathrm{Sb}_{2} \mathrm{O}_{3}\right)$, as synergistic flame retardant, are frequently added to HIPS polymers. Nevertheless, the presence of brominated flame retardants (BFRs) (such as TBBPA and DPE) and synergists $\left(\mathrm{Sb}_{2} \mathrm{O}_{3}\right)$ in HIPS makes it difficult to be recycled because of their potential health risk and environmental impacts if treated inadequately [4]. In addition, according to the WEEE European Union directive, the plastic fraction of WEEE should be recycled or recovered [3]. Therefore, how to recycle WEEE has gained increasing attention around the world.

Pyrolysis has been proposed as a viable processing route for not only converting the organic compounds in WEEE plastics into fuels and chemical feedstock but also separating and recovering the metals from plastic fractions [1]. Noteworthy, when HIPS added with brominated flame retardant and $\mathrm{Sb}_{2} \mathrm{O}_{3}$ synergist (Br-HIPS) is pyrolyzed with neither additives nor catalysts, a large amount of brominated compounds, such as $\mathrm{SbBr}_{3}, \mathrm{HBr}$ and organic brominated compounds, would exist in the oil product [4]-[9]. The presence of brominated compounds, especially the organic brominated compounds, in the oils would reduce their quality and hinder their reuse [5] [6]. Therefore, lots of debromination methods, effective catalysts and additives in the pyrolysis process of WEEE plastics have been investigated to reduce the bromine content from the oil products [1]. Bhaskar et al. synthesized the composite $\mathrm{Fe}-\mathrm{C}$ and $\mathrm{Ca}-\mathrm{C}$ additives, which could effectively remove the brominated compounds from the pyrolysis oil products [8] [9]. Terakado and Hirasawa used the metal oxides in the pyrolysis of TBBPA and printed circuit boards containing brominated flame retardants, respectively. They concluded that the addition of metal oxides could effectively suppress the formation of $\mathrm{HBr}$ and brominated organic compounds. The above research results indicated that the metal oxides could reduce the bromine content in the pyrolysis oil products by the neutralization reaction [10] [11]. Besides, there were many researches on zeolite catalysts used for the debromination in the pyrolysis of brominated WEEE plastics [5] [6]. Hall et al. investigated the catalytic pyrolysis of brominated flame-retarded HIPS and ABS by using HY zeolite and HZSM-5 zeolite, which proved that the zeolite catalysts could effectively catalytically reform the organ obrominated compounds and reduce the bromine contentin the pyrolysis oils [5].

In the practical operation, the impurities (such as metals) in WEEE and lots of cokes produced on the catalysts, would easily make the catalyst deactivate, which will increase the usage amount of catalysts and operating cost [12]. Two-stage combined pyrolysis and catalytic reforming process is proposed to be used for the pyrolysis recycling of WEEE plastics in this study. In the first stage, plastics are pyrolyzed for the purpose of depolymerization and decomposition. In the second stage, the pyrolysate of the plastics is reformed by the catalysts into valuable bromine-free liquid oil and gas. This pyrolysis and catalytic reforming process has the following merits. It is more practical for the recycling of raw WEEE plastics, which normally contain some impurities and metals that may deactivate the catalyst easily in the single catalytic pyrolysis process [13]. In addition, the residues and catalysts are separated, which have a potential to recycle the residues and metals, as well as to regenerate the catalyst, respectively.

Therefore, in the present study, the performance of small-scale two-stage combined pyrolysis and catalytic reforming reaction system used for the pyrolysis recycling of Br-HIPS was investigated at both the pyrolysis and reforming temperature of $500^{\circ} \mathrm{C}$. Natural zeolite (NZ) and commercial HY zeolite (YZ), as well as synthesized iron oxide loaded natural zeolite (Fe-NZ) and iron oxide loaded HY zeolite (Fe-YZ) were selected as the catalysts. The effect of catalyst types on the product yield, the gas and oil product composition and the debromination efficiency of the oil products was evaluated in details. In addition, the detail debromination mechanism will be discussed.

\section{Experimental}

\subsection{Materials}

The feedstock sample was HIPS containing brominated flame retardant and $\mathrm{Sb}_{2} \mathrm{O}_{3}$ as a synergist. The bromi- 
nated flame retardant was decabromodiphenyl ethane (DDE). The sample will be referred to as Br-HIPS. The samples were rectangular; with a size of $2 \mathrm{~mm}$ width and $3 \mathrm{~mm}$ length. The proximate analysis and ultimate analysis of the Br-HIPS sample is shown in Table 1.

The catalysts were natural zeolite (NZ), iron oxide loaded natural zeolite (Fe-NZ), HY zeolite (YZ) and iron oxide loaded HY zeolite (Fe-YZ). NZ and YZ catalysts were provided by the Nitto Funka Trading Company and Zeolyst International Company, respectively. Fe-NZ and Fe-YZ catalysts were prepared by the wetness impregnation method with $10 \mathrm{wt} \%$ iron oxide loading referred to the mass of catalysts. The addition of iron oxide was controlled through the concentration of the precursor solution. Firstly, NZ and YZ catalysts were outgassed for 1 hour under vacuum. Then, the desired amount of iron nitrate $\left(\mathrm{Fe}\left(\mathrm{NO}_{3}\right)_{3} \cdot 9 \mathrm{H}_{2} \mathrm{O}\right)$ was dissolved in deionized water, to which a predetermined weight of NZ and YZ was added. This solution was continuously stirred at the temperature of $60^{\circ} \mathrm{C}$ for 24 hours. Subsequently, the suspension was stirred in a rotary vacuum evaporator at the temperature of $60^{\circ} \mathrm{C}$ until the water was completely evaporated. The catalysts were then dried at $110^{\circ} \mathrm{C}$ for 24 hours. The dry-based catalyst was calcined at $550^{\circ} \mathrm{C}$ in air for 4 hours at a heating rate of $5^{\circ} \mathrm{C} / \mathrm{min}$ [9] [14].

\subsection{Experimental Setup and Procedures}

The experimental apparatus was composed of a pyrolyzer, a packed-bed catalytic reformer, a condenser, two condensate samplers and a gas scrubbing bottle, as shown in Figure 1. The pyrolyzer and the reformer were made of stainless steel (SUS316) and covered with an electric heater. The inner diameter and inner height of the pyrolyzer are $30 \mathrm{~mm}$ and $280 \mathrm{~mm}$, respectively. The dimensions of reformer is $25 \mathrm{~mm}$ (diameter) $\times 200 \mathrm{~mm}$ (height). During the experiments, $50 \mathrm{~g}$ Br-HIPS sample and $10 \mathrm{~g}$ each catalyst (20 wt\% of the sample) were fed into the pyrolyzer and reformer, respectively. Subsequently, the pyrolyzer and reformer were heated to $500^{\circ} \mathrm{C}$ at a heating rate of $50^{\circ} \mathrm{C} / \mathrm{min}$ under the $\mathrm{N}_{2}$ carrier gas with a flow rate of $50 \mathrm{ml} / \mathrm{min}$. In the all experiments, the reactor temperature was held at the target temperature for 2 hours. The oil product was condensed in two oil collectors, which were cooled by ice water solution. In order to capture $\mathrm{HBr}$, the gaseous products were scrubbed with $50 \mathrm{ml} 0.1 \mathrm{~mol} / \mathrm{L} \mathrm{NaOH}$ solution in the third trap before being collected in a tedlar bag. The replicated experiments have been performed for each result under same reaction conditions.

\subsection{Analytical Methods}

The elemental analysis was conducted by using a Micro Corder JM 10 Elemental Analyzer. The bromine content was determined by an air combustor coupled with DionexICS-1100 ion chromatography fitted with a Shodex ICS1-904E column according to JIS K 7392. The amounts of antimony and titanium were determined by the inductively coupled plasma mass spectrometry (ICP-MS). The antimony and bromine contents in the cokes were measured by a scanning electron microscopy with energy disperse X-ray analysis (SEM-EDX).

The crystalline structures of the four catalysts were characterized by a powder X-ray diffraction (XRD) analysis. XRD measurements were performed using a Rigaku Ultimal V diffractometer with the CuKa radiation $(\lambda=1.540)$ at $40 \mathrm{kV}$ and $40 \mathrm{~mA}$. Besides, the surface structure was characterized by the scanning electron microscopy (SEM). The surface area and textural properties of the used catalysts were determined by $\mathrm{N}_{2}$ physical

\begin{tabular}{cccc}
\hline \multicolumn{3}{c}{ Table 1. Proximate analysis and ultimate analysis of the Br-HIPS sample. } \\
\hline Proximate analysis & wt $\%$ & Ultimate analysis & wt\% \\
\hline Moisture & 0.00 & $\mathrm{C}$ & 78.61 \\
Volatile matter & 98.13 & $\mathrm{H}$ & 7.11 \\
Fixed carbon & 0.34 & $\mathrm{O}$ & 0.75 \\
Ash & 1.53 & $\mathrm{~N}$ & 0.10 \\
& & $\mathrm{Br}$ & 9.30 \\
& & $\mathrm{Sb}$ & 3.77 \\
& & $\mathrm{Ti}$ & 0.36 \\
\hline
\end{tabular}




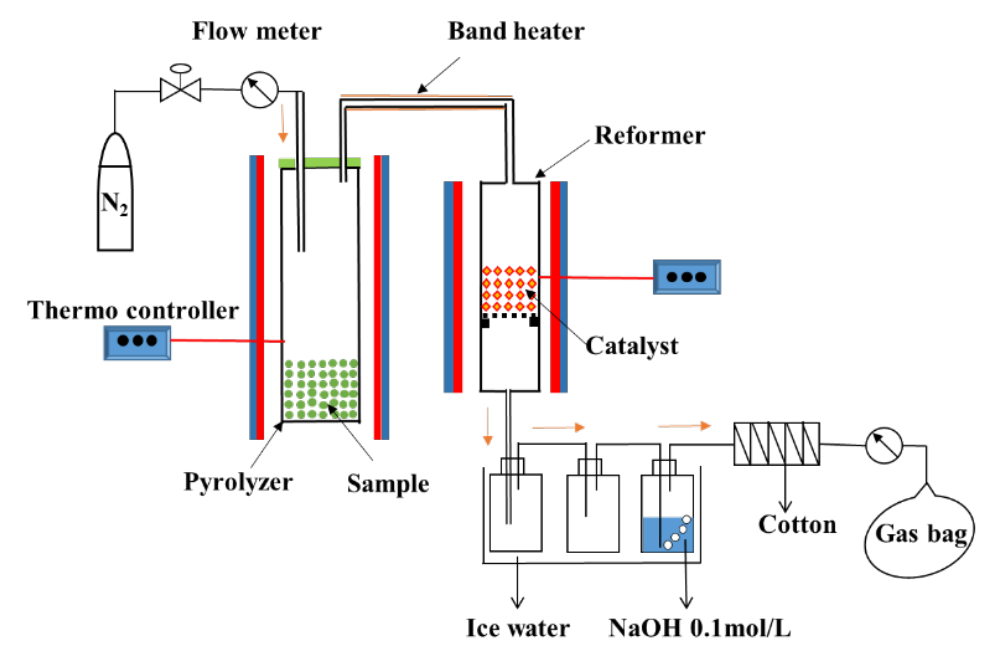

Figure 1. Schematic diagram of the pyrolysis and catalytic reforming apparatus.

adsorption at $77 \mathrm{~K}$, applying the Brunauer-Emmett-Teller (BET) method, using the Micromeritics Tristar 3020 equipment.

The weights of the char and coke were determined by the weight differences of the pyrolyzer and reformer after and before the experiments, respectively. The weight of the oil product was measured by the weight difference of the oil collectors after and before the experiments. The weight of the gas product was calculated by subtracting the weight of the char, coke and oil products from the total weight of the sample.

The composition of the oil product was analyzed by the gas chromatograph coupled with a mass spectrometer (GC-MS) (Shimadzu QP-2010). The column was an Rtx-5MS capillary column (30 m length, 0.25 mm id, 0.25 $\mu \mathrm{m}$ film thickness). The concentration of the each gas composition in the experiments was measured by a micro gas chromatograph fitted with a thermal conductivity detector (GC-TCD) (Agilent Micro 3000), and the yield of each component was calculated by the following equation.

$$
m_{i}=M_{i} \times \frac{C_{i}}{C_{\mathrm{N}_{2}}} \times \frac{V_{\mathrm{N}_{2}}}{22.4}
$$

where $m_{i}$ is the yield of the gas $i$ in the gas products, $M_{i}$ is the molar mass of each gas product; $C_{i}$ is the concentration of the gas $i$ in the gas products; $C_{\mathrm{N}_{2}}$ is the concentration of $\mathrm{N}_{2}$ in the gas products; $V_{\mathrm{N}_{2}}$ is the $\mathrm{N}_{2}$ flow rate $\times$ the flow time.

\section{Results and Discussion}

\subsection{Catalyst Characterization}

The parent NZ and YZ catalysts and the catalysts obtained by incorporation of iron oxide loadings (Fe-NZ and Fe-YZ) were characterized by SEM, XRD and BET to determine the effect of iron oxide addition on the catalyst properties. The $\mathrm{N}_{2}$ adsorption isotherms and the pore structure properties of the catalysts are shown in Figure 2 and Table 2, respectively. It can be clearly found that the surface area, the pore volume and the average pore diameter decreased after the iron oxide loaded on NZ and YZ. It may be attributed to the part of $\mathrm{Fe}_{2} \mathrm{O}_{3}$ distributed on the outer surface of NZ and YZ to reduce their outer surface area. The others are transferred into the pores of the catalysts so that the pore diameter and the volume also reduced.

The parent catalysts and the impregnated catalysts are verified by XRD, which was presented in Figure 3. According to the PDF card of the standard diffraction datum, the XRD pattern of NZ and YZ indicated their MOR structure and FAU structure, respectively. The Fe wetness impregnation procedure seemed not to affect their crystallinity. The iron oxide peak designated at $2 \theta$ value of $33^{\circ}$ was not observed in the Fe loaded $\mathrm{NZ}$ and YZ catalysts. Hence, it indicated that Fe was highly dispersed in the zeolite matrix and the loaded iron oxide with too small particle sizes on the surface of the zeolites was difficult to be identified by XRD method. It 
Table 2. Pore structure properties of NZ, Fe-NZ, YZ and Fe-YZ catalysts.

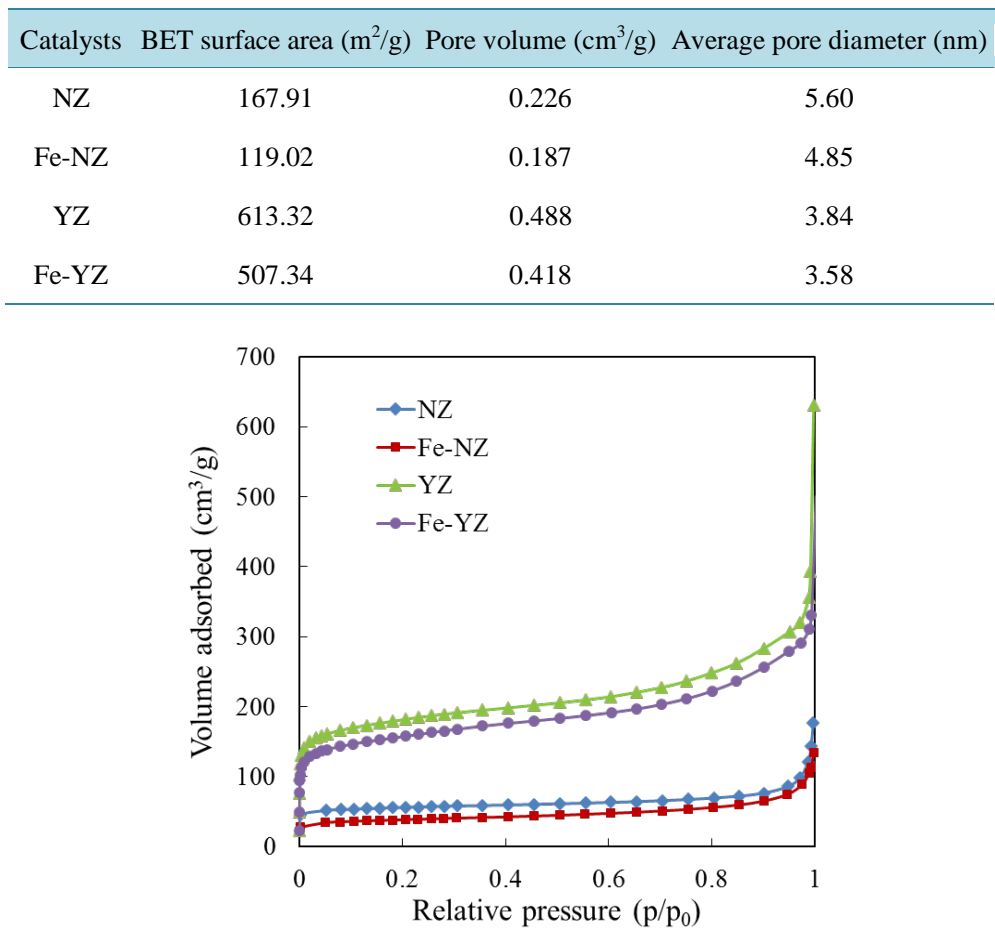

Figure 2. $\mathrm{N}_{2}$ adsorption isotherms at $77 \mathrm{~K}$ of NZ, Fe-NZ, YZ and Fe-YZ catalysts.

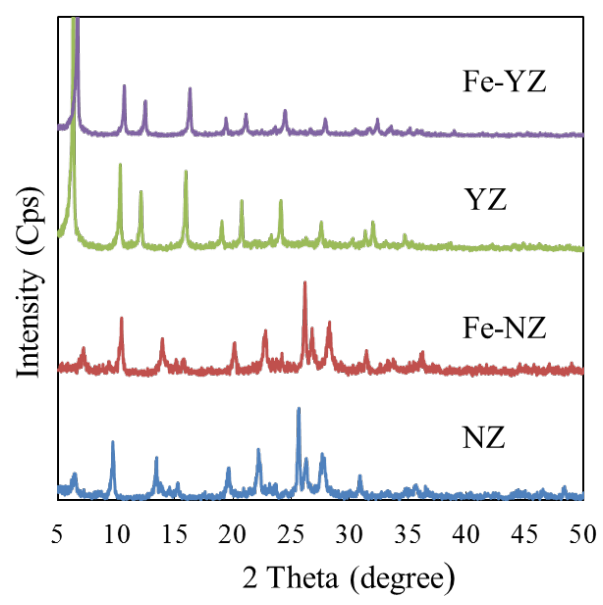

Figure 3. XRD patterns of NZ, Fe-NZ, YZ and Fe-YZ catalysts.

should be noted that the XRD diffraction bands shifted slightly to higher d values (inter-planar spacing) for the iron-substituted catalysts. It originated from an increase in the lattice parameters for the Fe loaded NZ and YZ catalysts, which indicated that the iron was successfully incorporated into NZ and YZ catalysts [15].

Figure 4 shows the SEM images of NZ, YZ, Fe-NZ and Fe-YZ catalysts for the surface characteristic analysis. From these characterizations, the porous and textural surface structure of NY and YZ catalysts could be observed. Additionally, YZ catalyst was consisted of small uniform crystals, while NY catalyst was formed by different size particles and crystals with different shapes and morphology. After the loading of iron oxide, the surfaces of both Fe-NZ and Fe-YZ became rougher and some large particles can be observed on Fe-NZ and Fe-YZ as a result of the agglomeration produced by the deposited iron oxides. Consequently, the result could confirm the reduction of the surface areas of Fe-NZ and Fe-YZ after the iron oxide loading. 


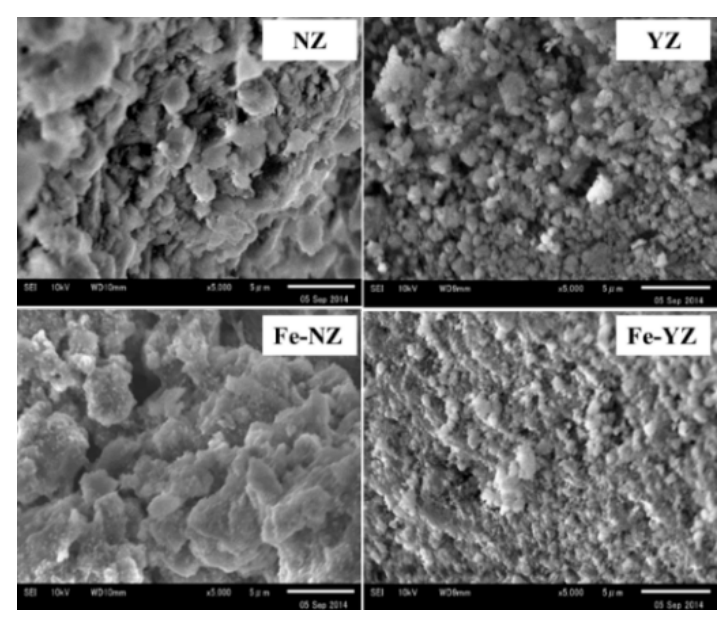

Figure 4. SEM photographs of NZ, YZ, Fe-NZ and Fe-YZ catalyst.

\subsection{The Effect of the Catalyst Types on the Product Yield and the Product Composition}

In the thermal pyrolysis of Br-HIPS, there would be lots of bromine content existing in the oil products, as reported [4]-[8]. The existence of brominated compounds in the oil products, especially the organic brominated compounds, would lower the oil quality and hinder reuse of the oil products, in this study, the two-stage combined pyrolysis and catalytic reforming of Br-HIPS was carried out to investigate the effect of NZ, Fe-NZ, YZ and Fe-YZ catalysts on the degradation of Br-HIPS and the debromination characteristics. The pyrolysis and catalytic reforming experiments were carried out in the absence and presence of NZ, Fe-NZ, YZ and Fe-YZ catalysts at the pyrolysis temperature of $500^{\circ} \mathrm{C}$ and the reforming temperature of $500^{\circ} \mathrm{C}$, respectively. In this system, Br-HIPS was thermally decomposed in the pyrolyzer, and then the pyrolysate flowed into the reformer, as shown in Figure 1. The product yield distribution was presented in Figure 5, which indicated that when Br-HIPS was pyrolyzed in the absence of the catalyst, the char, oil and gas yields were $15.9 \mathrm{wt} \%, 82.9 \mathrm{wt} \%$ and $1.2 \mathrm{wt} \%$, respectively. When the Br-HIPS was pyrolyzed in the presence of NZ, Fe-NZ, YZ and Fe-YZ, respectively, the oil yield decreased from $82.9 \mathrm{wt} \%$ to $73.6 \mathrm{wt} \%, 72.2 \mathrm{wt} \%, 56.9 \mathrm{wt} \%$ and $59.9 \mathrm{wt} \%$, respectively, while the coke yields increased to $5.5 \mathrm{wt} \%, 8.4 \mathrm{wt} \%, 16.8 \mathrm{wt} \%$ and $15.4 \mathrm{wt} \%$ from $0.0 \mathrm{wt} \%$, respectively. And the gas yields increased from $1.2 \mathrm{wt} \%$ to $5.2 \mathrm{wt} \%, 3.5 \mathrm{wt} \%, 10.2 \mathrm{wt} \%$ and $8.3 \mathrm{wt} \%$, respectively. On one hand, it was primarily related to the fact that these four zeolite catalysts possess the Lewis and Brønsted acidity and the catalytic activity [16]-[18]. Thus, they could catalytically reform the pyrolysate derived from the pyrolyzer and converted oil products into gases and coke. On the other hand, the increase of the coke yield was also attributed to the fact that the zeolite catalysts with the pore property could capture the inorganic brominated compounds, such as $\mathrm{SbBr}_{3}[5]$, which originally would be transferred into the oil products. The detail debromination mechanism will be discussed in the Section 3.3.

In addition, the maximum gas yield was achieved by using the $\mathrm{YZ}$ catalyst due to the strongest acidity and the largest surface area of YZ catalyst, compared with the other three catalysts (Table 2). Furthermore, when Fe-NZ and Fe-YZ catalysts were used, it was found that the gas yield became lower than that case of NZ and YZ usage, respectively. It is most likely attributed to the fact that iron oxide particles in NZ and YZ catalysts can not only reduced their surface areas and the pore sizes, but also would lowered the acidity and the activity of the parent catalysts. The reason could be attributed to the de-aluminization process during the calcination, which reduced the acid site density or it could be the partial exchange between iron ions with $\mathrm{H}^{+}$of the acidic zeolite [19]. As for the char yield, there was no obvious change regardless of whether catalysts were used or not. It might be originated from the fact that the thermal degradation of Br-HIPS mainly occurred in the pyrolyzer and the yield of char was only affected by the pyrolysis temperature.

The effect of the catalysts on the composition of the oil and gas products were investigated by GC-TCD and GC-MS, as shown in Table 3. As for the composition of the gas products, they are composed of hydrocarbons from $\mathrm{C}_{1}$ (methane), $\mathrm{C}_{2}$ (ethane and ethene) and $\mathrm{C}_{3}$ (propane and propene), along with small quantities of hydrogen. It can be seen that $\mathrm{C}_{2}-\mathrm{C}_{3}$ gases were the main fractions of gas products both in absence and presence of the catalysts. In general, the use of catalysts enhanced the amount of each gas composition, especially $C_{2}$ and $C_{3}$ gas 


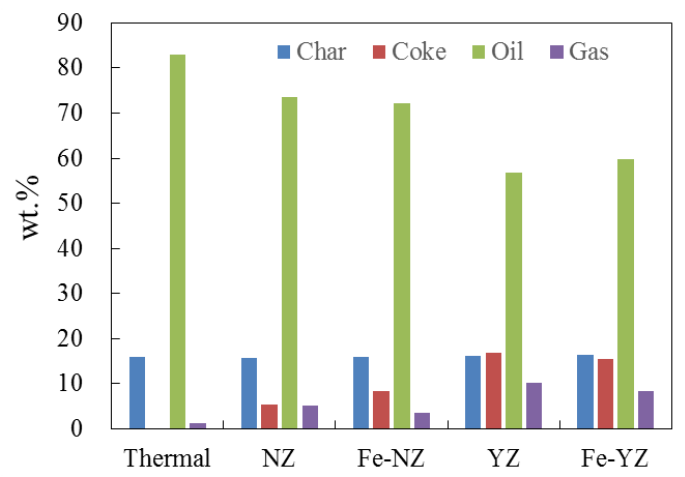

Figure 5. Effect of the catalyst types on the product yield.

fractions, which might be related to the shape selectivity of these catalysts (pore size). This significant increase in the gas yield in the presence of YZ, which was also reported by others [5], suggested the strong cracking ability of this catalysts, which was a consequence of its higher porosity and stronger acidity than the other catalysts. Furthermore, the use of iron oxide loaded catalysts (Fe-NZ and Fe-YZ) reduced the production of $\mathrm{C}_{2}$ and $\mathrm{C}_{3}$ fractions compared to the parent zeolite catalysts (NZ and $\mathrm{YZ}$ ). It further confirmed that the loading of iron oxide would weaken the cracking ability of the parent zeolite catalysts. It is worth mentioning that all catalysts enhanced the hydrogen production, which was most likely attributed to the hydrogen abstraction that took place during the aromatization reactions [6].

The oil products evolved from the pyrolysis of Br-HIPS in the absence and presence of catalysts were analyzed by GC-MS, and the main components are listed in Table 3. It indicated that the single-ring aromatic compounds were the major components of the oil products with or without the catalysts, such as toluene, styrene, cumene, ethylbenzene and xylenes etc., which is attributed to the structure property of HIPS polymer matrix. Whereas, when no catalyst was used, the amount of styrene monomer in the oil product was very small. In general, when polystyrene or high impact polystyrene without flame retardants is pyrolyzed, styrene monomer is often obtained as the main oil component, which is mainly due to its characteristics of the free radical mechanism, namely the $\beta$-scission followed by the depolymerization [20]-[22]. The low yield of the styrene monomer in the oil products may be originated from the flame retardant inhibiting the formation of styrene monomers due to the interaction between the polymer radicals and the flame retardants [4] [23]. When NZ and YZ catalysts were used, the yields of the styrene monomer became lower. The reason for this could be that NZ and YZ catalysts, especially YZ, showed a high catalytic efficiency on the cracking, the isomerization and the aromatization due to the acidic property and the micropore crystalline structure [24]. Additionally, when the iron oxide loaded catalysts (Fe-NZ and Fe-YZ) were applied, the concentration of styrene greatly increased, while the concentrations of ethlybenzene decreased. The distinct increase of the styrene content in the presence of the iron oxide loaded catalysts may be attributed to the fact that the degradation of the styrene backbone of HIPS took place after the anionic mechanism to form carbanion, as shown in Figure 6 [21].

Noteworthy, when Br-HIPS was pyrolyzed in the absence of a catalyst, $50.3 \mathrm{wt} \%$ single-ring aromatic compounds was obtained in the oil products. When $\mathrm{YZ}$ and Fe-YZ catalysts were used, the amount of valuable single-ring aromatic compounds decreased from $50.3 \mathrm{wt} \%$ to $20.6 \mathrm{wt} \%$ and $27.1 \mathrm{wt} \%$ while the production of two-ring aromatic compounds and multi-ring aromatic compounds significantly increased. However, when BrHIPS was pyrolyzed in the presence of NZ and Fe-NZ catalysts, the single-ring aromatic compounds only reduced from $50.3 \mathrm{wt} \%$ to $39.9 \mathrm{wt} \%$ and $44.5 \mathrm{wt} \%$ while the two-ring aromatic compounds and multi-ringaromatic compounds slightly increased. Williams et al. [19] reported that there were a large number of polycyclic aromatic hydrocarbons (PAH) in the pyrolysis oil of polystyrene that had been pyrolyzed in the presence of ZSM-5. Hall et al. [21] also observed that when Br-HIPS was pyrolyzed with YZ, the production of PAH in the oil products was obviously enhanced. Williams et al. [19] proposed that the formation of PAH in the polystyrene pyrolysis oil was attributed to the Diels-Alder reaction. Furthermore, the above results also indicated that YZ and Fe-YZ were more active than NZ and Fe-NZ in the case of the catalytic cracking while NZ and Fe-NZ catalysts did not greatly alter the pyrolysis products and therefore preserved the valuable single-ring aromatic compounds. 
Table 3. Main components of the gas and oil products determined by GCTCD and GC-MS (\% area) (wt\%/sample mass).

\begin{tabular}{|c|c|c|c|c|c|}
\hline Main products & Thermal & NZ & $\mathrm{Fe}-\mathrm{NZ}$ & $\mathrm{YZ}$ & $\mathrm{Fe}-\mathrm{YZ}$ \\
\hline \multicolumn{6}{|l|}{ Main gas components } \\
\hline $\mathrm{H}_{2}$ & 0.05 & 0.15 & 0.07 & 0.23 & 0.17 \\
\hline $\mathrm{CH}_{4}$ & 0.16 & 0.59 & 0.43 & 0.86 & 0.77 \\
\hline $\mathrm{C}_{2}$ & 0.32 & 1.53 & 0.98 & 2.86 & 2.75 \\
\hline $\mathrm{C}_{3}$ & 0.38 & 1.81 & 1.06 & 3.91 & 2.38 \\
\hline \multicolumn{6}{|l|}{ Main oil components } \\
\hline Total single ring compounds & 50.32 & 39.88 & 44.48 & 20.63 & 27.08 \\
\hline Toluene & 6.78 & 4.9 & 4.57 & 2.05 & 3.43 \\
\hline Styrene & 4.21 & 3.26 & 12.93 & 1.67 & 9.31 \\
\hline Cumene & 2.64 & 3.96 & 4.69 & 2.35 & 2.78 \\
\hline Ethylbenzene & 20.21 & 14.46 & 6.93 & 7.35 & 2.23 \\
\hline Xylenes & 6.73 & 5.96 & 6.86 & 1.74 & 2.37 \\
\hline Allylbenzene & 2.48 & 2.12 & 1.5 & 0.65 & 1.03 \\
\hline Propylbenzene & 2.91 & 1.05 & 1.76 & 1.43 & 1.94 \\
\hline$\alpha$-Methylstyrene & 3.11 & 1.61 & 1.23 & 1.02 & 1.48 \\
\hline Indane & 0.13 & 1.31 & 2.22 & 1.45 & 1.34 \\
\hline Diehtylbenzenes & 1.12 & 1.25 & 1.79 & 0.92 & 1.17 \\
\hline Total two ring compounds & 11.88 & 13.15 & 9.6 & 15.13 & 12.54 \\
\hline Biphenyl & 0.21 & 0.77 & 0.54 & 1.03 & 0.87 \\
\hline Naphthalene & 1.13 & 1.72 & 1.09 & 2.31 & 1.96 \\
\hline Methylnaphthalenes & 0.89 & 1.74 & 1.56 & 2.99 & 2.06 \\
\hline Bibenzyl & 0.6 & 0.51 & 0.43 & 1.85 & 1.33 \\
\hline 1,3-Diphenylpropane & 8.53 & 6.67 & 4.81 & 4.54 & 4.29 \\
\hline Ethylnaphthalenes & 0.2 & 0.98 & 0.63 & 1.49 & 1.12 \\
\hline Dimethylnaphthalenes & 0.32 & 0.76 & 0.54 & 0.92 & 0.91 \\
\hline Total multi ring compounds & 2.68 & 4.32 & 3.22 & 8.61 & 5.71 \\
\hline Phenylnaphthalenes & 0.43 & 0.92 & 0.87 & 1.87 & 1.01 \\
\hline Anthracene & 0.91 & 1.06 & 0.62 & 2.01 & 1.56 \\
\hline Ethenylanthracenes & 0.21 & 0.67 & 0.52 & 1.78 & 0.94 \\
\hline Terphenyls & 0.42 & 0.74 & 0.46 & 0.98 & 0.87 \\
\hline 1,3,5-Triphenylbenzene & 0.71 & 0.93 & 0.75 & 1.97 & 1.33 \\
\hline Total brominated compounds & 2.99 & 1.71 & 0.24 & 0.48 & 0.11 \\
\hline (1-Bromoethyl)benzene & 1.24 & 0.78 & 0.17 & 0.11 & 0.11 \\
\hline 3-Methylbenzyl bromide & 0.94 & 0.75 & 0.07 & 0.14 & n.d. \\
\hline 9-Bromoanthracene & 0.56 & n.d $d^{\mathrm{a}}$ & n.d. & 0.09 & n.d. \\
\hline 9,10-Dibromoanthracene & 0.25 & 0.18 & n.d. & 0.14 & n.d. \\
\hline
\end{tabular}

${ }^{\mathrm{a}}$ Not detected. 

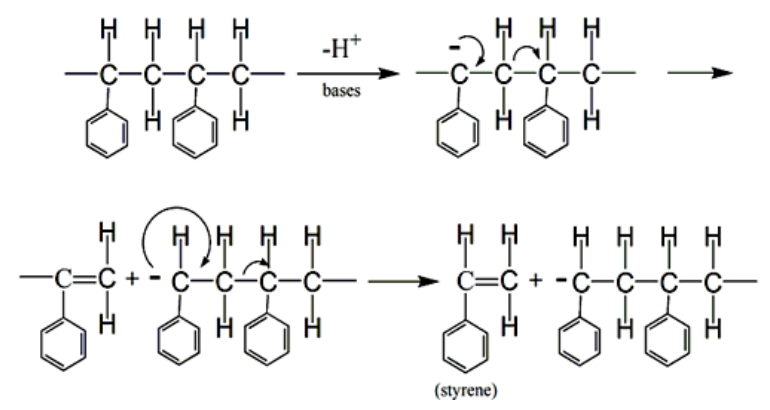

Figure 6. Base-catalyzed mechanism for polystyrene proposed by Ukei et al.

\subsection{The Effect of the Catalysts on the Bromine and Antimony Content in the Oil Products}

The total bromine and antimony contents in the pyrolysis oils were determined using a bomb calorimeter equipped with an ion chromatograph and ICP-MS after digestion of oil samples, respectively, as shown in Figure 7. During the pyrolysis of $\mathrm{Br}-\mathrm{HIPS}, \mathrm{HBr}, \mathrm{SbBr}_{3}, \mathrm{Br}_{2}$ and certain organic brominated compounds were produced. It should be worth mentioning that the brominated compounds (such as $\mathrm{HBr}$ ) in the gas products was not determined by the ion chromatograph. The similar results have been reported by Hall et al. [5] [6]. Additionally, Figure 7 obviously indicated that there was a high bromine content ( $7.6 \mathrm{wt} \%$ ) in each oil product, which means that large amounts (68.1 wt\%) of bromine was transferred to the oil products during the pyrolysis of Br-HIPS without catalysts. This demonstrated that the effective catalysts or additives were essential for removing bromine in an attempt to obtain bromine free oil products. When NZ and YZ catalysts were used, the bromine content in the oils decreased to $2.0 \mathrm{wt} \%$ and $1.4 \mathrm{wt} \%$, respectively. This significant decrease of the bromine content in the oil by YZ catalyst was a consequence of its higher porosity and stronger acidity, contributing to capture $\mathrm{SbBr}_{3}$ and catalytically crack the organ obrominated compounds [5] [6]. When Fe-NZ and Fe-YZ were used, the bromine content in the oils decreased from $7.6 \mathrm{wt} \%$ to $0.7 \mathrm{wt} \%$ and $0.6 \mathrm{wt} \%$, respectively. It indicated that after the iron oxide loading, the debromination performance of Fe-NZ and Fe-YZ got improved, which was possibly attributed to the neutralization reaction of loaded iron oxide with $\mathrm{HBr}$ derived from the degradation of $\mathrm{Br}-\mathrm{HIPS}$ [23]. The neutralization reaction can be shown as following.

$$
\mathrm{Fe}_{2} \mathrm{O}_{3}+6 \mathrm{HBr} \rightarrow 2 \mathrm{FeBr}_{3}+3 \mathrm{H}_{2} \mathrm{O}
$$

$\mathrm{Fe}_{2} \mathrm{O}_{3}$ was fixed on the surface and in the pore of Fe-NZ and Fe-YZ. Consequently, the solid-phase product $\mathrm{FeBr}_{3}$ also could be easily captured by Fe-NZ and Fe-YZ. As for Fe-NZ and Fe-YZ, the main debromination mechanism could be summarized as the capture of $\mathrm{FeBr}_{3}$ and $\mathrm{SbBr}_{3}$, as well as the catalytic reforming of the organ obrominated compounds, which originated from their porosity, iron oxide loading and acidity. In addition, the EDX analysis of spent NZ, Fe-NZ, YZ and Fe-YZ were carried out to conform the above debromination mechanism and compare the debromination performance of each catalyst. From Figure 7 and Figure 8, it is obviously demonstrated that the bromine removal ability of Fe-YZ was better than that of Fe-NZ. However, in the view of the cost reduction of the catalyst and preservation of the valuable single-ring aromatic compounds in the oil product, Fe-NZ was more effective and feasible for the feedstock recycling of Br-HISP by the pyrolysis process.

\section{Conclusion}

The effect of NZ, Fe-NZ, YZ and Fe-NZ catalysts on the product yield, the gas and oil product composition and the debromination efficiency of the oil products was investigated in the two-stage combined pyrolysis and catalytic reforming reactor at both pyrolysis and reforming temperatures of $500^{\circ} \mathrm{C}$. It could be concluded from the present study that the amount of bromine in the oil product could effectively be reduced in the presence of the catalysts. The loading of $\mathrm{Fe}_{2} \mathrm{O}_{3}$ on zeolite, such as Fe-NZ and Fe-YZ could enhance the debromination performance, in terms of the bromine content in the oils decreased from $7.6 \mathrm{wt} \%$ to $0.7 \mathrm{wt} \%$ and $0.6 \mathrm{wt} \%$, respectively. Compared with Fe-YZ, Fe-NZ did not greatly alter the pyrolysis products and therefore preserved the valuable single-ring aromatic compounds. Consequently, Fe-NZ was more effective and feasible for the feedstock recycling of Br-HISP by the pyrolysis process. The mechanism of bromine removal from the oil product was mainly 

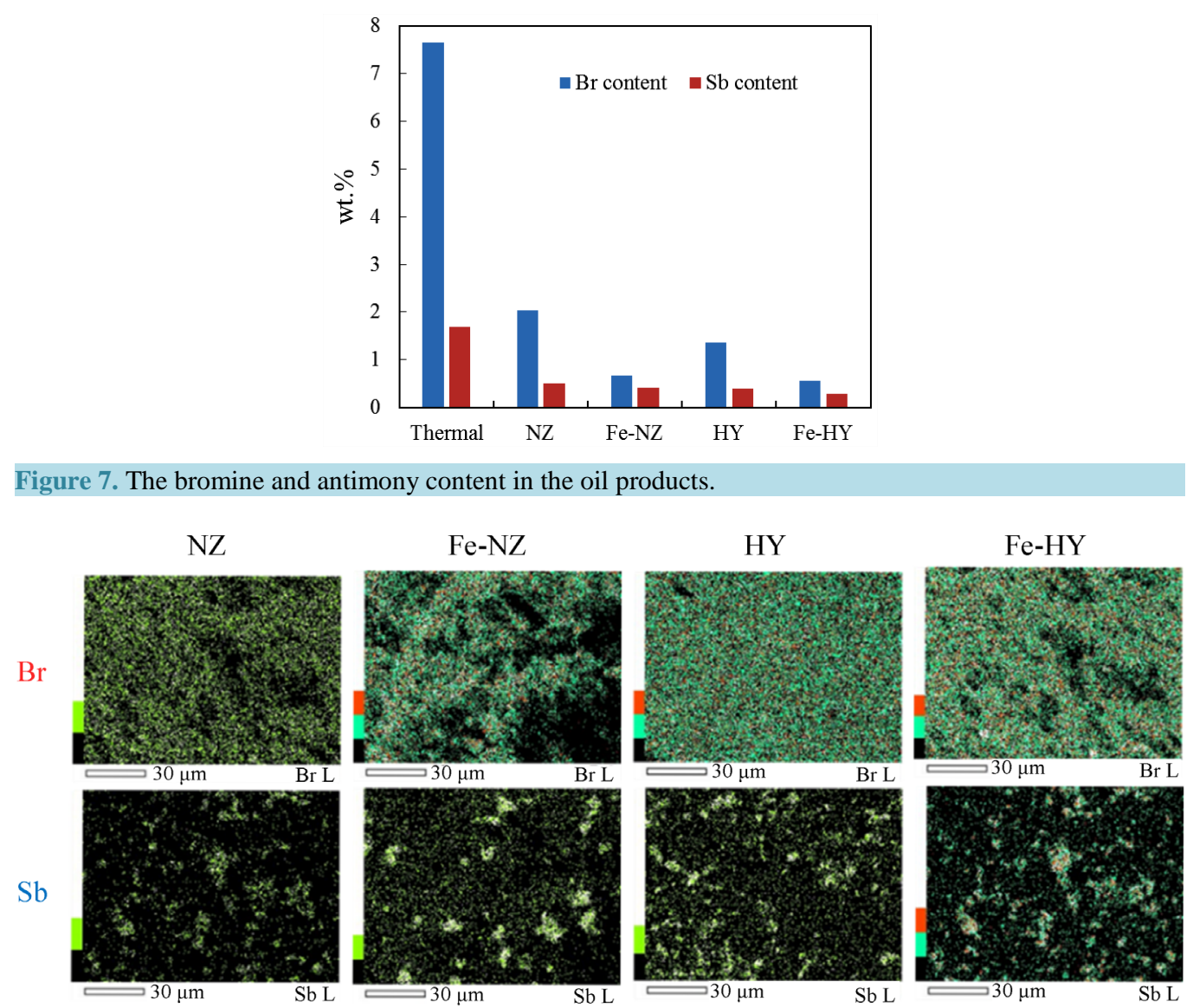

Figure 8. EDX analysis of spent NZ, Fe-NZ, YZ and Fe-YZcatalysts.

attributed to the zeolite pore capture of produced $\mathrm{SbBr}_{3}$ and $\mathrm{FeBr}_{3}$, the catalytic reforming of the organ obrominated compounds, as well as the neutralization reaction of the iron oxide with $\mathrm{HBr}$ derived from the decomposition of Br-HIPS.

\section{Acknowledgements}

The authors would like to thank Dr. Tohru Kamo of Advanced Industrial Science and Technology (AIST), Tsukuba, Japan for his valuable help and discussion.

\section{References}

[1] Yang, X.N., Sun, L.S., Xiang, J., Hu, S. and Su, S. (2013) Pyrolysis and Dehalogenation of Plastics from Waste Electrical and Electronicequipment (WEEE): A Review. Waste Management, 33, 462-473. http://dx.doi.org/10.1016/j.wasman.2012.07.025

[2] Martinho, G., Pires, A., Saraiva, L. and Ribeiro, R. (2012) Composition of Plastics from Waste Electrical and Electronic Equipment (WEEE) by Direct Sampling. Waste Management, 32, 1213-1217. http://dx.doi.org/10.1016/j.wasman.2012.02.010

[3] Ongondo, F.O., Williams, I.D. and Cherrett, T.J. (2011) How Are WEEE Doing? A Global Review of the Management of Electrical and Electronic Wastes. Waste Management, 31, 714-730. http://dx.doi.org/10.1016/j.wasman.2010.10.023

[4] Jakab, E., Uddin, Md.A., Bhaskar, T. and Sakata, Y. (2003) Thermal Decomposition of Flame-Retarded High Impact Polystyrene. Journal of Analytical and Applied Pyrolysis, 68-69, 83-99. http://dx.doi.org/10.1016/S0165-2370(03)00075-5

[5] Hall, W.J. and Williams, P.T. (2008) Removal of Organobromine Compounds from the Pyrolysisoils of Flame Retarded Plastics Using Zeolite Catalysts. Journal of Analytical and Applied Pyrolysis, 81, 139-147. http://dx.doi.org/10.1016/j.jaap.2007.09.008 
[6] Hall, W.J., Miskolczi, N., Onwudili, J. and Williams, P.T. (2008) Thermal Processing of Toxic Flame-Retarded Polymers Using a Waste Fluidized Catalytic Cracker (FCC) Catalyst. Energy \& Fuels, 22, 1691-1697. http://dx.doi.org/10.1021/ef800043g

[7] Miskolczi, N., Hall, W.J., Angyal, A., Bartha, L. and Williams, P.T. (2008) Production of Oil with Low Organobromine Content from the Pyrolysisof Flame Retarded HIPS and ABS Plastics. Journal of Analytical and Applied Pyrolysis, 83, 115-123. http://dx.doi.org/10.1016/j.jaap.2008.06.010

[8] Bhaskar, T., Matsui, T., Azhar Uddin, Md., Kaneko, J., Muto, A. and Sakata, Y. (2003) Effect of $\mathrm{Sb}_{2} \mathrm{O}_{3}$ in Brominated Heating Impact Polystyrene (HIPS-Br) on Thermal Degradation and Debromination Byiron Oxide Carbon Composite Catalyst (Fe-C). Applied Catalysis B: Environmental, 43, 229-241. http://dx.doi.org/10.1016/S0926-3373(02)00306-5

[9] Bhaskar, T., Matsui, T., Kaneko, J., Uddin, Md.A., Muto, A. and Sakata, Y. (2002) Novel Calcium Based Sorbent (Ca-C) for the Dehalogenation (Br, Cl) Process during Halogenated Mixed Plastic (PP/PE/PS/PVC and HIPS-Br) Pyrolysis. Green Chemistry, 4, 372-375. http://dx.doi.org/10.1039/b203745a

[10] Terakado, O., Ohhashi, R. and Hirasawa, M. (2011) Thermal Degradation Study of Tetrabromobisphenol A under the Presence Metaloxide: Comparison of Bromine Fixation Ability. Journal of Analytical and Applied Pyrolysis, 91, 303309. http://dx.doi.org/10.1016/j.jaap.2011.03.006

[11] Terakado, O., Ohhashi, R. and Hirasawa, M. (2013) Bromine Fixation by Metal Oxide in Pyrolysis of Printed Circuit Board Containing Brominated Flame Retardant. Journal of Analytical and Applied Pyrolysis, 103, 216-221. http://dx.doi.org/10.1016/j.jaap.2012.10.022

[12] Castano, P., Elordi, G., Olazar, M., Aguayo, A.T., Pawelec, B. and Bilbao, J. (2011) Insights into the Coke Deposited on HZSM-5, H $\beta$ and HY Zeolites during the Cracking of Polyethylene. Applied Catalysis B: Environmental, 104, 91100. http://dx.doi.org/10.1016/j.apcatb.2011.02.024

[13] Park, Y., Namioka, T., Sakamoto, S., Min, T.J., Roh, S.A. and Yoshikawa, K. (2010) Optimum Operating Conditions for a Two-Stage Gasification Process Fueled by Polypropylene by Means of Continuous Reactor over Ruthenium Catalyst. Fuel Processing Technology, 91, 951-957. http://dx.doi.org/10.1016/j.fuproc.2009.10.014

[14] Adam, F., Wong, J.T. and Ng, E.P. (2013) Fast Catalytic Oxidation of Phenol over Iron Modified Zeolite L Nanocrystals. Chemical Engineering Journal, 214, 63-67.http://dx.doi.org/10.1016/j.cej.2012.10.017

[15] Joshi, P.N., Awate, S.V. and Shiralkar, V.P. (1993) Partial Isomorphous Substitution of Fe ${ }^{3+}$ in the LTL Framework. The Journal of Physical Chemistry, 97, 9749-9753. http://dx.doi.org/10.1021/j100140a035

[16] Lee, S.Y., Yoon, J.H., Kim, J.R. and Park, D.W. (2001) Catalytic Degradation of Polystyrene over Natural Clinoptilolite Zeolite. Polymer Degradation and Stability, 74, 297-305. http://dx.doi.org/10.1016/S0141-3910(01)00162-8

[17] Dawood, A. and Miura, K. (2002) Catalytic Pyrolysis of $\gamma$-Irradiated Polypropylene (PP) over HY Zeolite for Enhancing the Reactivity and the Product Selectivity. Polymer Degradation and Stability, 76, 45-52. http://dx.doi.org/10.1016/S0141-3910(01)00264-6

[18] Bagri, R. and Williams, P.T. (2002) Catalytic Pyrolysis of Polyethylene. Journal of Analytical and Applied Pyrolysis, 63, 29-41. http://dx.doi.org/10.1016/S0165-2370(01)00139-5

[19] Botas, J.A., Serrano, D.P., García, A., de Vicente, J. and Ramos, R. (2012) Catalytic Conversion of Rapeseed Oil into Raw Chemicals and Fuels over Ni- and Mo-Modified Nanocrystalline ZSM-5 Zeolite. Catalysis Today, 195, 59-70. http://dx.doi.org/10.1016/j.cattod.2012.04.061

[20] Lee, S.Y., Yoon, J.H., Kim, J.R. and Park, D.W. (2002) Degradation of Polystyrene Using Clinoptilolite Catalysts. Journal of Analytical and Applied Pyrolysis, 64, 71-83. http://dx.doi.org/10.1016/S0165-2370(01)00171-1

[21] Ukei, H., Hirose, T., Horikawa, S., Takai, Y., Taka, M., Azuma, N. and Ueno, A. (2000) Catalytic Degradation of Polystyrene into Styrene and a Design of Recyclable Polystyrene with Dispersed Catalysts. Catalysis Today, 62, 67-75. http://dx.doi.org/10.1016/S0920-5861(00)00409-0

[22] Jung, S.H., Kim, S.J. and Kim, J.S. (2013) The Influence of Reaction Parameters on Characteristics of Pyrolysis Oils from Waste High Impact Polystyrene and Acrylonitrile-Butadiene-Styrene Using a Fluidized Bed Reactor. Fuel Processing Technology, 116, 123-129. http://dx.doi.org/10.1016/j.fuproc.2013.05.004

[23] Jung, S.H., Kim, S.J. and Kim, J.S. (2012) Fast Pyrolysis of a Waste Fraction of High Impact Polystyrene (HIPS) Containing Brominated Flame Retardants in a Fluidized Bed Reactor: The Effects of Various Ca-Based Additives $\left(\mathrm{CaO}, \mathrm{Ca}(\mathrm{OH})_{2}\right.$ and Oyster Shells) on the Removal of Bromine. Fuel, 95, 514-520.

http://dx.doi.org/10.1016/j.fuel.2011.11.048

[24] Seo, Y.H., Lee, K.H. and Shin, D.H. (2003) Investigation of Catalytic Degradation of High-Density Polyethylene by Hydrocarbon Group Type Analysis. Journal of Analytical and Applied Pyrolysis, 70, 383-393. http://dx.doi.org/10.1016/S0165-2370(02)00186-9 